\title{
Genetic diversity of Taenia saginata (Cestoda: Cyclophyllidea) from Lao People's Democratic Republic and northeastern Thailand based on mitochondrial DNA
}

Oranuch Sanpool ${ }^{1,2}$, Rutchanee Rodpai ${ }^{1}$, Pewpan M. Intapan ${ }^{1 *}$, Lakkhana Sadaow ${ }^{1}$, Tongjit Thanchomnang ${ }^{2}$, Sakhone Laymanivong ${ }^{3}$, Wanchai Maleewong ${ }^{1}$ and Hiroshi Yamasaki ${ }^{4^{*}}$

\begin{abstract}
Background: Taenia saginata is a tapeworm found in cattle worldwide. Analysis of genetic diversity in different geographical populations of $T$. saginata not only helps to understand the origin, transmission and spread of this organism, but also to evaluate the selection pressures acting on T. saginata and how it is responding to them. However, there are few reports of the genetic variability of $T$. saginata populations in different regions of the world, including Lao PDR and Thailand. We report the genetic diversity of T. saginata populations in Lao PDR and northeastern Thailand together with sequences of $T$. saginata from other countries deposited in GenBank.

Results: Mitochondrial cox 1 sequence analysis revealed that 15 and 8 haplotypes were identified in 30 and 21 T. saginata isolates from Lao PDR and northeastern Thailand, respectively. Fifty-three haplotypes were identified from 98 sequences. Phylogenetic tree and haplotype network analyses revealed that global isolates of $T$. saginata were genetically divided into five groups (A, B, C1, C2 and D). Taenia saginata isolates from Lao PDR and northeastern Thailand belonged to either Group A or B. Taenia saginata from western Thailand clustered in groups C1, C2 and D, and populations from the northeast and western Thailand were found to be genetically distinct. Taenia saginata isolates in Lao PDR and Thailand were also found to be genetically diverse but the degree of genetic differentiation was low.

Conclusions: Taenia saginata populations from Lao PDR and northeastern Thailand are genetically distinct from the population in western Thailand and it is proposed that $T$. saginata has been dispersed by different transmission routes in Southeast Asia.
\end{abstract}

Keywords: Taenia saginata, Beef tapeworm, Genetic diversity, Haplotypes, Distribution, Lao PDR, Thailand

\section{Background}

Taeniosis is a parasitic zoonosis caused by infection with Taenia saginata, Taenia solium or Taenia asiatica [1, 2]. Taenia saginata, known as the beef tapeworm, has a global distribution which includes Thailand $[3,4]$ and Lao PDR $[5,6]$. The intermediate host of the parasite is cattle and larval cysticerci are found in the muscle tissue of

\footnotetext{
* Correspondence: pewpan@kku.ac.th; hyamasak@nih.go.jp 'Department of Parasitology and Research and Diagnostic Center for Emerging Infectious Diseases, Faculty of Medicine, Khon Kaen University, Khon Kaen 40002, Thailand

${ }^{4}$ Department of Parasitology, National Institute of Infectious Diseases, Ministry of Health, Labour and Welfare, Tokyo 162-8640, Japan

Full list of author information is available at the end of the article
}

the host. Humans can become infected by ingestion of a cysticercus in raw or undercooked beef which then develops into an adult tapeworm in the small intestine. The adult tapeworm sheds gravid proglottids filled with eggs, which pass into the environment in feces and are degraded to release the eggs. Once eggs are ingested by the intermediate cattle host, the larval oncospheres in the eggs hatch in the small intestine and migrate to skeletal muscle where they develop into cysticerci which are infectious to humans. Most patients infected with $T$. saginata have an active discharge of gravid proglottids and occasionally present with epigastric pain, nausea, weight loss and poor appetite [2]. Cattle infected with $T$. 
saginata can cause economic losses in terms of food production [7-10] and trade restriction [11].

Information on the global genetic diversity of $T$. saginata is very limited. Mitochondrial DNA has been used as a genetic marker for detection of intraspecific variation or cryptic species [12], and cytochrome $c$ oxidase subunit 1 gene $(\operatorname{cox} 1)$ is a commonly used marker for studying geographical populations of $T$. saginata $[4,13$, 14]. Anantaphruti et al. [4] reported that 14 haplotypes were identified from $73 \mathrm{~T}$. saginata isolates from northern and northeastern regions of Thailand based on the partial cox 1 sequences (924 bp). Although the distribution range of $T$. saginata is known for Lao PDR, which borders Thailand $[5,6]$, no evidence of genetic variation of $T$. saginata has been reported to date.

In this study, we performed molecular-phylogenetic tree and haplotype network analyses based on the complete cox 1 sequences $(1,620 \mathrm{bp})$ of $51 \mathrm{~T}$. saginata isolates from Lao PDR and northeastern Thailand. We also included 47 sequences already deposited in GenBank, to better understand the genetic diversity and character of $T$. saginata populations in these countries.

\section{Methods}

\section{Parasite samples}

The 51 taeniid samples examined in this study were collected in Lao PDR $(n=30)$ and northeastern Thailand $(n=$ 21). In Lao PDR, specimens were obtained from patients with taeniosis in Xebungfai District, Khammouane Province, central Lao PDR (1704'287"N, 104 54'544" E) during a parasitological survey conducted by the Lao Ministry of Health in June 2015 [15]. Patients with taeniid eggs detected in the feces by the Kato-Katz technique [16] were treated with a single dose of praziquantel $(40 \mathrm{mg} / \mathrm{kg})$ and saturated magnesium sulfate solution. The dose of praziquantel was increased because taeniosis patients are commonly co-infected with liver fluke (Opisthorchis viverrini) in Lao PDR [17]. The proglottids obtained by deworming were washed with normal saline solution, fixed in 70\% ethanol, and stored at $-20{ }^{\circ} \mathrm{C}$ until use. Taeniid proglottids from Thailand were obtained from patients who lived in northeastern regions of Thailand and had been admitted to Srinagarind Hospital, Faculty of Medicine, Khon Kaen University, Khon Kaen, Thailand (2010-2015) and had been stored in $70 \%$ ethanol at $-20{ }^{\circ} \mathrm{C}$.

\section{Molecular identification of taeniid parasites}

Genomic DNA samples were extracted from individual taeniid proglottids using a DNeasy Blood \& Tissue kits (Qiagen, Hilden, Germany) according to the manufacturer's instructions. The complete cox 1 gene $(1,620 \mathrm{bp})$ was amplified by PCR using the primers Taenia trnW/F (5'-GTT ATG TTA GAC TAG ATG TTT TCA-3' for the Taenia transfer RNA-Try gene) and Taenia rrnl/R (5'-TCC ACT
AAG CAT AAT GCA AAA GGC-3' for Taenia ribosomal RNA large subunit gene) [18]. TaKaRa Ex Taq (Hot Start version, Takara Bio, Shiga, Japan) was used as a DNA polymerase. PCR amplification consisted of an initial denaturation step of $98{ }^{\circ} \mathrm{C}$ for $30 \mathrm{~s}$, followed by 35 cycles of $94{ }^{\circ} \mathrm{C}$ for $30 \mathrm{~s}, 58{ }^{\circ} \mathrm{C}$ for $30 \mathrm{~s}, 72{ }^{\circ} \mathrm{C}$ for $90 \mathrm{~s}$, with a final cycle of $72{ }^{\circ} \mathrm{C}$ for $5 \mathrm{~min}$. Amplicons were cleaned using ExoSAP-IT (Affimetrix/USB, Santa Clara, CA, USA) and used as templates for direct DNA sequencing. Samples for DNA sequencing were prepared using a BigDye Terminator Cycle Sequencing Ready Reaction kit (Life Technologies, Foster City, CA, USA) by primer walking and run on a $3730 \times 1$ DNA Analyzer (Life Technologies, Carlsbad, CA USA).

\section{Population genetics analysis}

The $T$. saginata cox 1 sequences were aligned using ClustalW [19] and a phylogenetic tree was constructed using the maximum likelihood algorithm implemented in MEGA 6. Tamura-Nei $(\mathrm{TN} 93+\mathrm{G}+\mathrm{I})$ was used as the best-fit substitution model [20] and support for groupings within the tree was evaluated by bootstrapping with 1,000 replicates [21]. A network analysis was performed using the median-joining method included in the Network software version 5.0.0.0 (Fluxus Technology Ltd., www.fluxus-engineering.com).

The following measures for population genetics based on complete $T$. saginata $\operatorname{cox} 1$ sequences from this study and GenBank were calculated: genetic variability at polymorphic sites between populations $(S)$, haplotype numbers $(h)$, haplotype diversity $(H d)$, nucleotide diversity $(\pi)$, population mutation rates based on the number of segregation sites $(\theta \omega)$ and mean number of pairwise differences $(\theta \pi)$ [22-25] were calculated using DnaSP version 4.0 [26]. Statistical analysis to distinguish between DNA sequences evolving randomly (neutrality) and those evolving under a non-random process was done using Tajima's D [27] and Fu's Fs tests [28].

\section{Results}

All of the 51 taeniid isolates collected in Lao PDR and northeastern Thailand were identified as $T$. saginata based on the diagnostic nucleotide (= adenine) at position 723 of $\operatorname{cox} 1$ [29], although slight intra-population variation was observed. BLAST searches also revealed that the 51 sequences showed high homology (> 99\%) to T. saginata sequences deposited in GenBank. The complete sequence analysis revealed that 15 and 8 haplotypes were detected in 30 and $21 \mathrm{~T}$. saginata isolates from Lao PDR and northeastern Thailand, respectively. Fifty-three haplotypes were identified in 98 sequences, which included 47 sequences from GenBank. The haplotypes, haplotype frequencies, and accession numbers for the $98 \mathrm{~T}$. saginata cox 1 sequences are presented in Table 1. 
Table 1 Taenia saginata haplotypes and their frequencies in Lao PDR, Thailand and other countries

\begin{tabular}{|c|c|c|}
\hline Haplotype & $\begin{array}{l}\text { Haplotype } \\
\text { frequency }\end{array}$ & $\begin{array}{l}\text { Sample (Country) code/ } \\
\text { GenBank accession number }\end{array}$ \\
\hline $\mathrm{H} 1$ & 1 & T2 (THA)/KY290351 \\
\hline $\mathrm{H} 2$ & 1 & T3 (THA)/KY290352 \\
\hline $\mathrm{H} 3$ & 8 & $\begin{array}{l}\text { T4, T6, T7, T8, T13, T16, T17, } \\
\text { T19 (THA)/KY290353 }\end{array}$ \\
\hline $\mathrm{H} 4$ & 1 & T5 (THA)/KY290354 \\
\hline H5 & 1 & T9 (THA)/KY290355 \\
\hline H6 & 4 & $\begin{array}{l}\text { T10, T20, T21, T22 (THA)/ } \\
\text { KY290356 }\end{array}$ \\
\hline H7 & 3 & T11, T14, T24 (THA)/KY290357 \\
\hline H8 & 2 & T12, T23 (THA)/KY290358 \\
\hline H9 & 1 & L1.1 (LAO) $/$ KY290359 \\
\hline $\mathrm{H} 10$ & 1 & L1.2 (LAO) $/$ KY290360 \\
\hline $\mathrm{H} 11$ & 13 & $\begin{array}{l}\text { L1.3 } 3^{a}, L 2.1^{b}, L 2.3^{b}, L 4, L 8, L 10, \\
\text { L17, L18, L19, L31, L65.1, L67, } \\
\text { L71 (LAO)/KY290361 }\end{array}$ \\
\hline $\mathrm{H} 12$ & 1 & L2.2 ${ }^{\mathrm{b}}(\mathrm{LAO}) / \mathrm{KY} 290362$ \\
\hline $\mathrm{H} 13$ & 1 & L2.4 b $^{\mathrm{L}}(\mathrm{LO}) / \mathrm{KY} 290363$ \\
\hline $\mathrm{H} 14$ & 1 & L3 (LAO)/KY290364 \\
\hline $\mathrm{H} 15$ & 1 & L5 (LAO)/KY290365 \\
\hline H16 & 3 & L6, L12, L73 (LAO)/KY290366 \\
\hline $\mathrm{H} 17$ & 1 & L7 (LAO)/KY290367 \\
\hline $\mathrm{H} 18$ & 2 & L9, L11 (LAO)/KY290368 \\
\hline $\mathrm{H} 19$ & 1 & L13 (LAO)/KY290369 \\
\hline $\mathrm{H} 2 \mathrm{O}$ & 1 & L14 (LAO)/KY290370 \\
\hline $\mathrm{H} 21$ & 1 & L15 (LAO)/KY290371 \\
\hline $\mathrm{H} 22$ & 1 & L16 (LAO)/KY290372 \\
\hline $\mathrm{H} 23$ & 1 & L65.2 (LAO)/KY290373 \\
\hline $\mathrm{H} 24$ & 7 & $\begin{array}{l}\text { AB107240 (IDN), AB465245 } \\
\text { (ETH), AB465246 (KOR), AB465247 } \\
\text { (THA), AB465248 (THA), AB644391 } \\
\text { (JPN), AB820291 (DII) }\end{array}$ \\
\hline $\mathrm{H} 25$ & 1 & AB984348 (CHN) \\
\hline $\mathrm{H} 26$ & 1 & AB821273 (ETH) \\
\hline $\mathrm{H} 27$ & 1 & AB465243 (ECU) \\
\hline $\mathrm{H} 28$ & 1 & AY684274 (Africa, not specified) \\
\hline $\mathrm{H} 29$ & 10 & $\begin{array}{l}\text { AB107244 (THA), AB275143 (KHM), } \\
\text { AB107242 (BEL), AB107247 (CHN), } \\
\text { AB465231 (THA), AB465233 (THA), } \\
\text { AB465234 (THA), AB465241 (KHM), } \\
\text { AB533168 (CHN), AB465232 (THA) }\end{array}$ \\
\hline $\mathrm{H} 30$ & 1 & AB107239 (CHN) \\
\hline H31 & 1 & AB984351 (CHN) \\
\hline $\mathrm{H} 32$ & 1 & AB645845 (THA) \\
\hline $\mathrm{H} 33$ & 1 & AB465242 (THA) \\
\hline $\mathrm{H} 34$ & 1 & AB465240 (IDN) \\
\hline H35 & 1 & AB271695 (MNG) \\
\hline H36 & 1 & AB107238 (ECU) \\
\hline
\end{tabular}

Table 1 Taenia saginata haplotypes and their frequencies in Lao PDR, Thailand and other countries (Continued)

\begin{tabular}{|c|c|c|}
\hline$\overline{\mathrm{H} 37}$ & 2 & AB107237 (BRA), AB465238 (BRA) \\
\hline $\mathrm{H} 38$ & 1 & AB533169 (CHN) \\
\hline $\mathrm{H} 39$ & 1 & AB533172 (CHN) \\
\hline $\mathrm{H} 40$ & 1 & AB107243 (NPL) \\
\hline $\mathrm{H} 41$ & 1 & AB107241 (ETH) \\
\hline $\mathrm{H} 42$ & 1 & AY195858 (Africa, not specified) \\
\hline $\mathrm{H} 43$ & 1 & AB533171 (CHN) \\
\hline $\mathrm{H} 44$ & 1 & AB465237 (ETH) \\
\hline $\mathrm{H} 45$ & 1 & AB066495 (CHN) \\
\hline $\mathrm{H} 46$ & 1 & AB984350 (CHN) \\
\hline $\mathrm{H} 47$ & 1 & AB984347 (CHN) \\
\hline $\mathrm{H} 48$ & 1 & AB465239 (THA) \\
\hline $\mathrm{H} 49$ & 1 & AB984346 (CHN) \\
\hline $\mathrm{H} 50$ & 2 & AB465235 (THA), AB465236 (THA) \\
\hline $\mathrm{H} 51$ & 1 & AB533173 (THA) \\
\hline $\mathrm{H} 52$ & 1 & AB107246 (BRA) \\
\hline $\mathrm{H} 53$ & 1 & AB107245 (THA) \\
\hline
\end{tabular}

$\overline{\mathrm{a}, \mathrm{b}}$ Three (L1.1-L1.3) and four (L2.1-L2.4) tapeworms were expelled from two patients in Lao PDR. Such a situation is not common, but it is possible to find taeniosis patients with two and more adult tapeworms in endemic areas in Lao PDR and Thailand [34]

Note: For GenBank sequences (H24-H53), the numbers in the "Haplotype frequency" column indicate the numbers analyzed, not haplotype frequency Abbreviations: BEL Belgium, BRA Brazil, CHN China, DJ Djibouti, ECU Ecuador, ETH Ethiopia, IDN Indonesia, JPN Japan, KHM Cambodia, KOR Korea, LAO Lao PDR, MNG Mongolia, NPL Nepal, THA Thailand

Phylogenetic tree analysis using the 98 sequences indicated that global isolates of $T$. saginata could be genetically divided into five groups: A, B, D and two subgroups (C1 and C2) (see Additional file 1: Figure S1). Groups B and $\mathrm{C} 1$ diverged at the base of the phylogenetic tree. Although Group A branched off from Group B, the bootstrap values were not high. Group D diverged from subgroup C2. Groups A and B were composed of $T$. saginata populations from Lao PDR and northeastern Thailand. Subgroups C1 and C2 consisted of isolates from western Thailand and other geographical locations around the world. Group D was composed of a few $T$. saginata from western Thailand, which included Bangkok. It was unclear whether the patients had acquired the T. saginata infection in Bangkok or if they were just living in Bangkok. There was no common haplotype for $T$. saginata populations from western Thailand and other geographically different countries.

In addition to phylogenetic tree analysis, the medianjoining network also revealed that $T$. saginata isolates from around the world could be divided into five groups. Taenia saginata from Lao PDR and northeastern Thailand were separated in two scattered groups, Groups A and B, which were linked to each other (Fig. 1). Group A was composed 


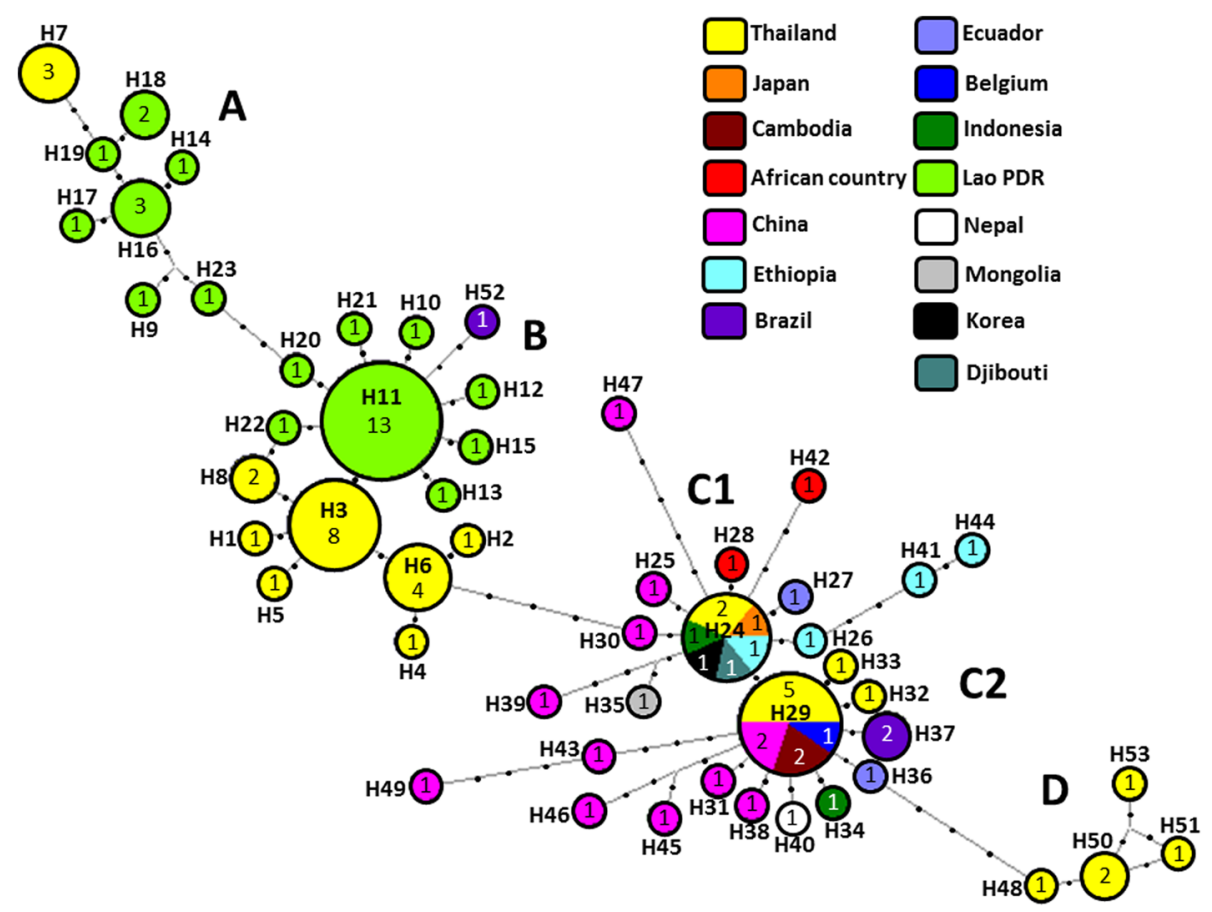

Fig. 1 Haplotype network of Taenia saginata from Lao PDR, Thailand and other countries. The size of the circles corresponds to the frequency of the haplotypes identified. Dots denote the number of nucleotide substitutions. Countries where T. saginata was collected are color-coded

of seven haplotypes (H9, H14, H16-H19 and H23) from Lao PDR and one haplotype (H7) from northeastern Thailand. Group B formed a firework-shaped structure around the predominant haplotypes (Lao H11 and Thai H3). Although one haplotype (H52) from Brazil was included in Group B, the phylogenetic relationship between T. saginata from these countries is unknown. Subgroup C1 was composed of a dominant haplotype (H24) from western Thailand, Japan, Korea, Indonesia, Djibouti and Ethiopia, as well as other haplotypes from China (H25, H30, H39 and H47), Mongolia (H35), Ecuador (H27), Ethiopia (H26, H41 and H44), and unspecified African countries (H28 and H42). Haplotype $\mathrm{H} 29$ was predominant in subgroup $\mathrm{C} 2$ and was composed of isolates from western Thailand, Cambodia, China and Belgium, and other haplotypes were from China $(\mathrm{H} 31, \mathrm{H} 38, \mathrm{H} 43, \mathrm{H} 45, \mathrm{H} 46$ and H49), western Thailand (H32 and H33), Indonesia (H34), Nepal (H40), Ecuador (H36) and Brazil (H37). Subgroups $\mathrm{C} 1$ and $\mathrm{C} 2$ were closely linked and formed firework-type structures around the two predominant haplotypes H24 and $\mathrm{H} 29$, respectively. Interestingly, Group D was composed of a few haplotypes (H48, H50, H51 and H53) from Kanchanburi Province, western Thailand and Bangkok, and T. saginata from northeastern and western Thailand were genetically distinct populations.

To estimate the genetic diversity in $T$. saginata populations from Lao PDR and northeastern Thailand, several population genetics indices based on the complete cox 1 sequences are presented in Table 2. The number of T. saginata haplotypes identified from Lao PDR and northeastern Thailand was 15 and 8, respectively, and the number of segregation sites was $20(1.23 \%)$ in Lao PDR and $10(0.67 \%)$ in northeastern Thailand. The overall number of haplotypes was 53 out of 98 sequences and 57 sites (3.79\%) were segregated. The haplotype diversity $(H d)$ was as high as $0.926 \pm 0.038$ and $0.819 \pm$ 0.064 in $T$. saginata populations from Lao PDR and northeastern Thailand, respectively. The global $H d$ $(0.968 \pm 0.020)$ was also high in $T$. saginata including the western Thai population $(0.868 \pm 0.076)$. In contrast, the nucleotide diversity $(\pi)$ was as low as $0.00252 \pm$ 0.0003 and $0.0015 \pm 0.00034$ in T. saginata from Lao PDR and northeastern Thailand, respectively. Overall the nucleotide diversity of haplotypes of $T$. saginata worldwide was as low as $0.00381 \pm 0.00021$, including the western Thai population $(0.0236 \pm 0.00041)$. $\theta \pi$ was less than $\theta \omega$ in $T$. saginata populations from Lao PDR and northeastern Thailand. Neutrality in $T$. saginata populations from Lao PDR and northeastern Thailand was not significant by Tajima's $D$ test $(-0.66964, P=0.10$, and $-0.66053, P=0.10)$ and Fu's $F$ s test $(-1.670, P=0.094)$. However, a pairwise Fu's $F s$ test showed a significant value $(-10.078, P<0.0001)$ in the Lao population. In haplotypes overall, Tajima's D value $(-2.31270, P=0.01)$ and a Fu's $F s$ value $(-21.042$, $P<0.0001)$ were significant. 
Table 2 Genetic diversity of Taenia saginata populations from Lao PDR, Thailand and other countries

\begin{tabular}{llllllllll}
\hline Populations & No. of samples & $h$ & $S(\%)$ & $H d$ & $\pi$ & $\theta \omega$ & $\theta \pi$ & Tajima's $D(P$-value $)$ & Fu's Fs $(P$-value $)$ \\
\hline Lao PDR & 30 & 15 & $20(1.23)$ & $0.926 \pm 0.038$ & $0.00252 \pm 0.00030$ & 5.048 & 4.078 & $-0.66964(P=0.10)$ & $-10.078(P<0.0001)^{*}$ \\
Northeastern Thailand & 21 & 8 & $10(0.67)$ & $0.819 \pm 0.064$ & $0.0015 \pm 0.00034$ & 2.780 & 2.248 & $-0.66053(P=0.10)$ & $-1.670(P=0.094)$ \\
Western/Central Thailand & 14 & 8 & $11(0.68)$ & $0.868 \pm 0.076$ & $0.00236 \pm 0.00041$ & 3.459 & 3.824 & $0.41614(P=0.10)$ & $-1.195(P=0.139)$ \\
$\begin{array}{l}\text { Northeastern Thailand } \\
\text { and Lao PDR }\end{array}$ & 51 & 24 & $21(1.40)$ & $0.915 \pm 0.025$ & $0.00226 \pm 0.00023$ & 4.667 & 3.402 & $-0.86683(P=0.10)$ & $-14.288(P<0.0001)^{*}$ \\
$\begin{array}{l}\text { World except for Lao } \\
\text { PDR and Thailand }\end{array}$ & 33 & 25 & $44(2.72)$ & $0.968 \pm 0.020$ & $0.00245 \pm 0.00037$ & 10.841 & 3.962 & $-2.31270(P=0.01)^{*}$ & $-21.042(P<0.0001)^{*}$ \\
All samples & 98 & 53 & $57(3.80)$ & $0.960 \pm 0.010$ & $0.00381 \pm 0.00021$ & 11.053 & 5.726 & $-1.60729(P=0.10)$ & $-43.930(P<0.0001)^{*}$
\end{tabular}

Abbreviations: $h$ haplotype numbers, $S$ number of segregation sites, $H d$ haplotype diversity, $\pi$ nucleotide diversity, $\theta \omega$ Watterson's theta based on $S, \theta \pi$ theta based on $\pi$

${ }^{*} P<0.05$

\section{Discussion}

In this study, we present molecular evidence of $T$. saginata infection in people in central Lao PDR and northeastern Thailand. We explored genetic diversity based on the complete cox 1 sequences of $T$. saginata populations from these regions and also included $T$. saginata data available from GenBank. To our knowledge, this is the first molecular identification and genetic diversity analysis of T. saginata from Lao PDR.

Phylogenetic tree and haplotype network analysis both revealed that $T$. saginata could be genetically divided into five groups and that $T$. saginata populations from Lao PDR and northeastern Thailand belonged to Group A and Group B. Subgroup C1 included the western Thai population, and Group D was also composed of western Thai isolates, but was differentiated from subgroup C2 . Taenia saginata populations from northeastern and western Thailand are geographically and genetically isolated and, to date, there is no evidence that they are sympatrically distributed in Thailand. It has been suggested that haplotype H11 may be an ancestral haplotype and that other haplotypes in the Lao population have diverged from it (Fig. 1). Subgroups $\mathrm{C} 1$ and $\mathrm{C} 2$ are composed of the predominant haplotypes (H24 and H29) and many haplotypes with low substitution rates. The predominant haplotypes were also detected in China, suggesting that either haplotype (H24 or H29) may be an ancestral haplotype in these areas. In contrast, the phylogenetic relationships between Lao (H11) and Brazilian haplotypes (H52), the Thai $T$. saginata (H48) and Ecuadorian haplotypes (H36), and many of the global T. saginata isolates are unclear in Subgroups $\mathrm{C} 1$ and $\mathrm{C} 2$. Further study using other molecular markers is necessary to explain the complex phylogenetic relationships that exist between these $T$. saginata populations.

The $h$ and $\pi$ values in T. saginata from northeastern Thailand were lower than those from the Lao population. $\theta \pi$ was less than $\theta \omega$ in T. saginata populations from Lao PDR and northeastern Thailand. While the results of Tajima's D test were not significant in the Lao and northeastern Thai populations, Fu's Fs test showed that the Lao population is genetically differentiated $(-10.078, P<0.0001)$. This discrepancy between the two statistical tests is considered to explain why more haplotypes were detected compared with the number of segregated sites, and indicated that the genetic diversity in the Lao population was high. However, compared with other global $T$. saginata isolates, the degree of genetic differentiation in the Lao and northeastern Thai populations was low. This also supports the finding that Groups A and $B$ are linked to each other, in particular, haplotype H6 in Group B was linked to haplotype H30 from China in Subgroup C1. Group B formed a firework-like structure, which was differentiated by the small base substitution rate around predominant haplotypes $\mathrm{H} 3$ and $\mathrm{H} 11$. Taenia saginata populations are dispersed in different geographic localities where genetic variation is influenced by the genetic bottleneck effect that arises from decreases in the population size. However, because the sample-size that was examined in this study was small, further study using more samples from around the world is necessary to more accurately clarify the effect of such genetic events in geographically different populations.

Anantaphruti et al. [4] identified 14 haplotypes in 73 $T$. saginata isolates from northern and northeastern Thailand based on partial cox 1 sequences ( $924 \mathrm{bp})$. In their study, haplotypes A and B were predominant, and haplotype A was found in ten countries, including Thailand. These authors proposed that haplotype A shared the same ancestor as $T$. saginata populations from around the world. However, the findings of our network analysis differ from those in their report because the complete $\operatorname{cox} 1$ sequence of their haplotype B is not available, and the haplotype in our study corresponding to their haplotype $B$ has not been identified. Nonetheless, their haplotype A is identical to haplotype H29 in our study, but it was only found in Thailand, Belgium, China and Cambodia as shown in Fig. 1. This discrepancy can probably be attributed to the different 
lengths of cox 1 sequences because we analyzed the complete sequence $(1,620 \mathrm{bp})$, whereas only $924 \mathrm{bp}$ was analyzed previously [4].

The fact that genetically different $T$. saginata populations are distributed in Lao PDR and Thailand is probably closely associated with the artificial movement of cattle as an intermediate host. The artificial movement of cattle may have played an important role in the dispersal of liver fluke Fasciola species in Asia [30, 31]. To explain the geographically distinct nature of the T. saginata populations in Lao PDR and Thailand, the following scenario is possible: $T$. saginata originating in southern provinces of China might have been transmitted, via northwestern Thailand and Myanmar, to the western regions of Thailand (western route), and via northern Lao PDR and Vietnam to northeastern regions of Thailand (eastern route). Network analysis using more T. saginata specimens from different Asian countries, including China, is necessary to verify this scenario and to provide a more detailed estimate of the genetic diversity of $T$. saginata. The sample size in population genetics analysis can modulate the neutrality [32] and the size of the target gene can also interfere with population genetic indices as discussed above.

While taeniosis has a low impact on human health, it is an important zoonosis that can cause serious economic losses in cattle [7-11]. Consequently, understanding the population genetics of the parasite will help to elucidate transmission patterns and to develop control measures [33].

\section{Conclusions}

Taenia saginata from Lao PDR and northeastern Thailand showed high haplotype diversity, but the degree of genetic differentiation was low. Lao and northeastern Thai populations were also found to be genetically distinct form the T. saginata population in western Thailand, suggesting that $T$. saginata is spread by different transmission routes in Southeast Asia.

\section{Additional file}

Additional file 1: Figure S1. The maximum likelihood tree constructed from cox 1 sequences of $T$. saginata. Bootstrap scores (percentages of 1,000 replications) are presented at each node. Samples used to obtain the nucleotide sequences in this study are represented with sample codes in bold (KY290351-KY290373, see Table 1). Sequence data from GenBank are shown with accession numbers, country codes and haplotype names. Scale-bar indicates the number of nucleotide substitutions/site. (TIF 5144 kb)

\section{Acknowledgements}

This work was supported by Grants-in-Aid from a TRF Senior Research Scholar Grant, Thailand Research Fund grant number RTA5880001; the Higher Education Research Promotion and National Research University Project of Thailand, Office of the Higher Education Commission, Thailand, through the Health Cluster (SHeP-GMS); the Faculty of Medicine, Khon Kaen University (grant number TR57201) through WM and PMI, Post-Doctoral
Training Program of Graduate School and Khon Kaen University (grant no. 58101) to OS, and Research Program on Emerging and Re-emerging Infectious Diseases from Japan Agency for Medical Research and Development (Kansensho Jitsuyoka-Ippan, Nos.15fk0108025h0502 and 16fk0108309j0103) to HY.

\section{Funding}

This work was supported by Grants-in-Aid from a TRF Senior Research Scholar Grant, Thailand Research Fund grant number RTA5880001; the Higher Education Research Promotion and National Research University Project of Thailand, Office of the Higher Education Commission, Thailand, through the Health Cluster (SHeP-GMS); the Faculty of Medicine, Khon Kaen University (grant number TR57201) through WM and PMI, Post-Doctoral Training Program of Graduate School and Khon Kaen University (grant no. 58101) to OS, and Research Program on Emerging and Re-emerging Infectious Diseases from Japan Agency for Medical Research and Development (Kansensho Jitsuyoka-Ippan, Nos.15fk0108025h0502 and 16fk0108309j0103) to HY.

\section{Availability of data and materials}

All nucleotide sequences reported in this study have been deposited in the GenBank under accession numbers KY290351-KY290373.

\section{Authors' contributions}

OS, RR, PMI, LS, TT, SL, WM and HY conceived this study and planned the design of the protocols. OS, RR, LS, TT, SL, WM and HY performed sample collection and experiments. OS, RR and TT analyzed molecular data and prepared figures and tables. OS, WM and HY prepared the manuscript and reviewed the draft for important intellectual content, in particular the Discussion. All authors have read and approved the final manuscript.

\section{Competing interests}

The authors declare that they have no competing interests.

\section{Consent for publication}

Not applicable.

\section{Ethics approval and consent to participate}

The study protocol was approved by the Lao National Ethics Committee for Health Research, Ministry of Health, Lao PDR (No. 056/2015) and by the Khon Kaen University Ethics Committee for Human Research (HE561396 and HE581292). Each participant was informed of the study methods and the risks and benefits associated with treatment. Written consent was obtained from all adult participants and from parents or legal guardians of minors prior to enrolment in the study.

\section{Publisher's Note}

Springer Nature remains neutral with regard to jurisdictional claims in published maps and institutional affiliations.

\section{Author details}

${ }^{1}$ Department of Parasitology and Research and Diagnostic Center for Emerging Infectious Diseases, Faculty of Medicine, Khon Kaen University, Khon Kaen 40002, Thailand. 'Faculty of Medicine, Mahasarakham University, Maha Sarakham 44000, Thailand. ${ }^{3}$ Centre of Malariology, Parasitology and Entomology, Ministry of Health, Vientiane, Lao PDR. ${ }^{4}$ Department of Parasitology, National Institute of Infectious Diseases, Ministry of Health, Labour and Welfare, Tokyo 162-8640, Japan.

Received: 23 December 2016 Accepted: 6 March 2017

Published online: 11 March 2017

\section{References}

1. Ito A, Nakao M, Wandra T. Human taeniasis and cysticercosis in Asia. Lancet. 2003;362:1918-20

2. Sato MO, Nunes CM, Sato M, Waikagul J. Taenia. In: Xiao L, Ryan U, Feng Y, editors. Food Microbiology Series: Biology of Foodborne Parasites. New York: CRC Press; 2015. p. 463-80.

3. Jongwutiwes S, Putaporntip C, Chantachum N, Sampatanukul P. Jejunal perforation caused by morphologically abnormal Taenia saginata saginata infection. J Infect. 2004;49:324-8.

4. Anantaphruti M, Thaenkham U, Kusolsuk T, Maipanich W, Saguankiat S, Pubampen S, et al. Genetic variation and population genetics of Taenia 
saginata in north and northeast Thailand in relation to Taenia asiatica. J Parasitol Res. 2013;310605.

5. Conlan JV, Sripa B, Attwood S, Newton PN. A review of parasitic zoonoses in a changing Southeast Asia. Vet Parasitol. 2011;182:22-40.

6. Jeon HK, Yong TS, Sohn WM, Chai JY, Min DY, Yun CH, et al. Current status of human taeniasis in Lao People's Democratic Republic. Korean J Parasitol. 2013;51:259-63.

7. Grindle RJ. Economic losses resulting from bovine cysticercosis with reference to Botswana and Kenya. Trop Anim Health Prod. 1978;10:127-40.

8. Mann I. Environmental hygiene and sanitation based on the concept of primary health care as a tool for surveillance, prevention and control of taeniasis/cysticercosis. Curr Pub Health Res Tropics. 1983;36:127-40.

9. Regassa A, Abunna F, Mulugeta A, Megersa B. Major metacestodes in cattle slaughtered at Wolaita Soddo Municipal abattoir, southern Ethiopia: Prevalence, cyst viability, organ distribution and socioeconomic implications. Trop Anim Health Prod. 2009;41:1495-502.

10. Jahed Khaniki GR, Raei M, Kia EB, Haghi AM, Selseleh M. Prevalence of bovine cysticercosis in slaughtered cattle in Iran. Trop Anim Health Prod. 2010;42:141-3.

11. González SAC, Castillo JLR, Valencia GL, Hurtado RMB, Robles ESH, Navarro FJM. Prevalence of Taenia saginata larvae (Cysticercus bovis) in feedlot cattle slaughtered in a federal inspection type abattoir in Northwest México. Foodborne Pathog Dis. 2015;12:462-5.

12. Blouin MS. Molecular prospecting for cryptic species of nematodes: mitochondrial DNA versus internal transcribed spacer. Int J Parasitol. 2002;32:527-31.

13. Rostami S, Salavati R, Beech RN, Babaei Z, Sharbatkhori M, Harandi MF. Genetic variability of Taenia saginata inferred from mitochondrial DNA sequences. Parasitol Res. 2015;114:1365-76.

14. Solano D, Navarro JC, León-Reyes A, Benítez-Ortiz W, Rodríguez-Hidalgo R. Molecular analyses reveal two geographic and genetic lineages for tapeworms, Taenia solium and Taenia saginata, from Ecuador using mitochondrial DNA. Exp Parasitol. 2016;171:49-56.

15. Laymanivong $S$, Hangvanthong B, Insisiengmay B, Vanisaveth $V$, Laxachack $P$, Jongthawin J, et al. First molecular identification and report of genetic diversity of Strongyloides stercoralis, a current major soil-transmitted helminth in humans from Lao People's Democratic Republic. Parasitol Res. 2016;115:2973-80

16. Katz N, Chaves A, Pellegrino J. A simple device for quantitative stool thick-smear technique in schistosomiasis mansoni. Rev Inst Med Trop Sao Paulo. 1972;14:397-400.

17. Pungpak S, Viravan C, Radomyos B, Chalermrut K, Yemput C, Plookswasdi W, et al. Opisthorchis viverrini infection in Thailand: studies on the morbidity of the infection and resolution following praziquantel treatment. Am J Trop Med Hyg. 1997;56:311-4

18. Nakao M, Okamoto M, Sako Y, Yamasaki H, Nakaya K, Ito A. A phylogenetic hypothesis for the distribution of two genotypes of the pig tapeworm Taenia solium worldwide. Parasitology. 2002;124:657-62.

19. Thompson JD, Higgins DG, Gibson TJ. ClustalW: improving the sensitivity of progressive multiple sequence alignment through sequence weighting, position-specific gap penalties and weight matrix choice. Nucleic Acids Res. 1994;22:4673-80

20. Nei M, Kumar S. Molecular Evolution and Phylogenetics. New York: Oxford University Press; 2000.

21. Tamura K, Stecher G, Peterson D, Filipski A, Kumar S. MEGA6: Molecular Evolutionary Genetics Analysis version 6.0. Mol Biol Evol. 2013;30:2725-9.

22. Watterson GA. On the number of segregating sites in genetical models without recombination. Theor Popul Biol. 1975;7:256-76.

23. Nei M. Molecular Evolutionary Genetics. New York: Columbia University Press; 1987.

24. Tajima F. The effect of change in population size on DNA polymorphism. Genetics. 1989;123:597-601.

25. Misawa K, Tajima F. Estimation of the amount of DNA polymorphism when the neutral mutation rate varies among sites. Genetics. 1997;147:1959-64.

26. Rozas J, Sanchez-DelBarrio JC, Messeguer X, Rozas R. DnaSP, DNA polymorphism analyses by the coalescent and other methods. Bioinformatics. 2003;19:2496-7.

27. Tajima F. Statistical method for testing the neutral mutation hypothesis by DNA polymorphism. Genetics. 1989;123:585-95.

28. Fu YX. Statistical tests of neutrality of mutations against population growth, hitchhiking and background selection. Genetics. 1997;147:915-25.

29. Yamasaki H, Nakaya K, Nakao M, Sako Y, Ito A. Significance of molecular diagnosis using histopathological specimens in cestode zoonoses. Trop Med Health. 2007;35:307-21.
30. Ichikawa M, Bawn S, Maw NN, Htun LL, Thein M, Gyi A, et al. Characterization of Fasciola spp. in Myanmar on the basis of spermatogenesis status and nuclear and mitochondrial DNA markers. Parasitol Int. 2011;60:474-9.

31. Ichikawa M, Itagaki T. Dispersal of aspermic Fasciola sp. in Asia. Jpn J Vet Parasitol. 2013;11:71-9.

32. Subramanian $\mathrm{S}$. The effect of sample size on population genomics analyses - implications for the tests of neutrality. BMC Genomics. 2016;17:123.

33. Campbell G, Garcia HH, Nakao M, Ito A, Craig PS. Genetic variation in Taenia solium. Parasitol Int. 2006;55(Suppl):S121-6.

34. Anantaphruti M, Yamasaki H, Nakao M, Waikagul J, Watthanakulpanich D, Nuamtanong S, et al. Sympatric occurrence of Taenia solium, T. saginata, and T. asiatica, Thailand. Emerg Infect Dis. 2007;13:1413-6.

\section{Submit your next manuscript to BioMed Central and we will help you at every step:}

- We accept pre-submission inquiries

- Our selector tool helps you to find the most relevant journal

- We provide round the clock customer support

- Convenient online submission

- Thorough peer review

- Inclusion in PubMed and all major indexing services

- Maximum visibility for your research

Submit your manuscript at www.biomedcentral.com/submit
Biomed Central 